\title{
BMJ Open Contextual and individual inequalities of multimorbidity in Brazilian adults: a cross-sectional national-based study
}

To cite: Nunes BP, Chiavegatto Filho ADP, Pati S, et al. Contextual and individual inequalities of multimorbidity in Brazilian adults: a cross-sectional nationalbased study. BMJ Open 2017;7:e015885. doi:10.1136/ bmjopen-2017-015885

- Prepublication history and additional material for this paper are available online. To view these files please visit the journal online (http://dx.doi. org/10.1136/bmjopen-2017015885).

Received 6 January 2017 Revised 23 April 2017 Accepted 3 May 2017
CrossMark

For numbered affiliations see end of article.

Correspondence to

Dr Bruno P Nunes;

nunesbp@gmail.com

\section{ABSTRACT}

Objectives The study aims to evaluate the magnitude of multimorbidity in Brazilian adults, as well to measure their association with individual and contextual factors stratified by Brazilian states and regions.

Methods A national-based cross-sectional study was carried out in 2013 with Brazilian adults. Multimorbidity was evaluated by a list of 22 physical and mental morbidities (based on self-reported medical diagnosis and Patient Health Questionnaire-9 for depression). The outcome was analysed taking $\geq 2$ and $\geq 3$ diseases as cut-off points. Factor analysis (FA) was used to identify disease patterns and multilevel models were used to test association with individual and contextual variables. Results The sample comprised 60202 individuals. Multimorbidity frequency was $22.2 \%(95 \% \mathrm{Cl} 21.5$ to $22.9)$ for $\geq 2$ morbidities and $10.2 \%$ (95\% Cl 9.7 to 10.7$)$ for $\geq 3$ morbidities. In the multilevel adjusted models, females, older people, those living with a partner and having less schooling presented more multiple diseases. No linear association was found according to wealth index but greater outcome frequency was found in individuals with midrange wealth index. Living in states with higher levels of education and wealthier states was associated with greater multimorbidity. Two patterns of morbidities (cardiometabolic problems and respiratory/ mental/muscle-skeletal disorders) explained $92 \%$ of total variance. The relationship of disease patterns with individual and contextual variables was similar to the overall multimorbidity, with differences among Brazilian regions.

Conclusions In Brazil, at least 19 million adults had multimorbidity. Frequency is similar to that found in other Low and and Middle Income Countries. Contextual and individual social inequalities were observed.

\section{INTRODUCTION}

Multimorbidity is a current and worldwide public health problem mainly due to its high frequency ( $>60 \%$ in adults) and its association with negative outcomes. ${ }^{1-4}$ Most evidence is from high-income countries ${ }^{4}$ but results from Low and Middle-Income Countries (LMIC) are also available and increasing in the literature ${ }^{5-8}$ including epidemiological

\section{Strengths and limitations of this study}

- Comprehensive information about multimorbidity is still scarce in Brazil.

- As far as we are aware, this is among the first information about multimorbidity assessment of individual and contextual factors in a sample representative of the whole of Brazil.

- Multimorbidity is a challenge to the Brazilian health system due to its high frequency ( 2 in every 10 adults had $\geq 2$ diseases and 1 in every 10 had $\geq 3$ diseases, representing at least 19 million Brazilians) and the interplay of individual and contextual characteristics associated with the problem. Differences within the country were observed.

- Except for depression, other morbidities were evaluated by self-reporting, and we are not able to evaluate the contextual determinants at neighbourhood level.

information about multimorbidity in Brazilian cities. $^{9-11}$

Similar to international evidence, multimorbidity in Brazil is greater in females and increases according to age. Socioeconomic inequalities are also observed mainly related to educational differences, whereas multiple disease is more frequent in adults and elderly with less schooling and lower socioeconomic status. $^{1011}$

However, as far as we are aware, Brazilian evidence on multimorbidity for the entire country is scarce. Only recently, a paper evaluating epidemiology of multimorbidity in Brazil was published. ${ }^{12}$ The authors found a $24.2 \%$ (95\% CI 23.5 to 24.9$)$ prevalence rate of multimorbidity ${ }^{12}$ and correlates were similar to Brazilian located previous studies. $^{1011}$

Brazil is the fifth most populous country in the world with more than 200 million people. Furthermore, it is marked by historical social inequalities in different health aspects comprising the occurrence of chronic 
diseases including both physical and mental disorders. ${ }^{13-15}$ Understanding the occurrence and patterns of multimorbidity in the whole country can be relevant for Brazilian Unified Health System management of the challenges resulting from the rapid demographic and epidemiological transitions that have occurred in recent years. Additionally, identifying and comprehending the contextual and individual differences surrounding multimorbidity occurrence helps policy-makers to prioritise and promote health actions and interventions related to multimorbidity management.

Thus, the aim of this study was to evaluate the frequency and patterns of multimorbidity in Brazilian adults, as well to measure their association with individual and contextual factors stratified by Brazilian states and regions.

\section{METHODS}

This was a cross-sectional study using population-based data from the Brazilian National Health Survey (Pesquisa Nacional de Saúde (PNS)) carried out in Brazil in 2013. The survey was conducted by Instituto Brasileiro de Geografia e Estatística (IBGE) and the Ministry of Health. The sample is representative of people living in permanent housing, located in urban or rural areas, covering the country's five major geographical regions, its 26 states and Federal District.

Sampling was done in three stages, the first being the selection of census tracts, followed by households and, finally, individuals aged 18 or over. More details about the sampling process can be found elsewhere. ${ }^{16} 17$

Multimorbidity was evaluated by using a list of all 22 self-reported morbidities available in the study, 21 of which were based on self-reported medical diagnosis, while depression was based on the Patient Health Questionnaire-9. ${ }^{18}$ The question applied to measure each disease based on self-reported medical diagnosis was: "Has any physician already diagnosed you as having (each disease)?'.The following morbidities were included: high blood pressure (HBP); spinal column problem; hypercholesterolaemia; depression; diabetes; arthritis/ rheumatism; asthma/wheezy bronchitis; work-related muscle-skeletal disorders; cancer; other heart disease; stroke; kidney problem; heart attack; heart failure; bronchitis; angina; emphysema; other lung disease; bipolar disorder; other mental disease; schizophrenia; and obsessive-compulsive disorder (OCD). Multimorbidity was evaluated by two cut-off points as per the literature ${ }^{419}$ : $\geq 2$ and $\geq 3$ morbidities. Women who had HBP or diabetes only during pregnancy were considered as not having these diseases.

Independent variables were sex (male; female), age (continuous), skin colour (white, black, and brownAsian-Brazilian and indigenous were not shown because they represented less than $1.6 \%$ of the sample), marital status (without partner, with partner), schooling in years (0: no schooling; 1-8: incomplete primary school; 8-11: complete primary school and incomplete secondary school; $\geq 12$ : complete secondary school up to complete higher education), wealth index in quintiles (based on ownership of bathroom, car, motorcycle, refrigerator, washing machine, digital video disc player, television, landline telephone, microcomputer and microwave oven), private health plan (no, yes), geographical area (urban, rural); state-level education in terciles-proportion of literacy rate obtained from IBGE 2010 and state-level income in terciles (nominal income per capita-average monthly value-in permanent private housing obtained from IBGE 2010).

Statistical analyses were performed using Stata V.12.1 software and the suy command was used, which takes into consideration sample weights. Sample weights were defined for the primary sampling units, households and all inhabitants, as well as for the selected inhabitant. Complete information about PNS sample weights and sampling process have been published elsewhere. ${ }^{16} 17$ The results from the sample were expanded for the Brazilian population.

Descriptive analysis was based on the calculation of prevalence and its respective confidence intervals. Factor analysis (FA) was performed to identify patterns of morbidities. ${ }^{20}$ This analysis was based on tetrachoric correlation, this being more appropriate than Pearson's correlation for dichotomous variables. ${ }^{21}$ Before FA analysis, Kaiser-Meyer-Olkin (KMO) and Bartlett sphericity tests were used to evaluate the applicability of this approach. After the first evaluation of the model, some variables were encompassed (bronchitis, emphysema and other lung disease to other respiratory problemsCOPD) and others excluded (schizophrenia, OCD, another mental disease and another heart disease) to obtain a better model fit regarding KMO and Bartlett sphericity tests. Oblique (oblimin or promax) rotation was performed. To establish the number of components to be retained, we used Cattel graphics, Kaiser criteria (eigenvalue $>1$ ) and minimum explained variance $(>10 \%$ for each component). Variables with loadings $|\geq 0.3|$ were kept. ${ }^{22}$ Through factorial analysis, we obtained the predicted scores of morbidities (factors).

Multilevel models were performed to account for statelevel variance, with the individuals as the first level and the state of residence as the second level. First, the models were initially adjusted without inclusion of the independent variables (null model) to test the initial variance attributable to the state accounting for approximately $1 \%(\mathrm{p}<0.05)$ of variance for the four analyses (multimorbidity $\geq 2$; multimorbidity $\geq 3$, factor 1 and factor 2 ). Then, we performed a logistic regression model for multimorbidity ( $\geq 2$ and $\geq 3$ morbidities) and linear regression models to evaluate the association of factors (patterns) of diseases and independent variables. We included sex, age, skin colour, marital status, schooling in years, private health plan, geographical area, state-level education and income in these models. Stratified region-level analyses were performed to better understanding disparities among states. 
The study was approved by the National Research Ethics Commission on 8 July 2013, under no 10853812.7.0000.0008. All respondents signed a free and informed consent statement form prior to data collection.

\section{RESULTS}

The sample comprised 60202 adults. The most frequent diseases were HBP (22.3\%) and spinal column problem (19.0\%). Angina, emphysema, other lung disease, bipolar disorder, other mental disease, schizophrenia and OCD were present in less than $1 \%$ of the sample. Lung disease problems showed, on average, longer duration of disease. Greater comorbidities were observed for individuals with health problems (heart attack; heart failure and angina). The mean range of comorbidities was from 2.3 to 4.5 diseases (see online supplementary table 1).

Females comprised $55.1 \%$ of the sample and mean age was 43.7 years $(\mathrm{SD}=17.0)$, ranging from 18 to 101 . Most individuals reported white skin colour $(47.8 \%)$ followed by brown $(41.7 \%)$. Almost two-thirds lived with a partner. Out of the total sample, $45.2 \%$ had $\geq 12$ years of schooling and $13.9 \%$ had zero schooling. Less than one-third had a private health plan and $13.5 \%$ lived in rural areas (table 1 ). The mean average proportion of literacy rate at the state level was $7.3 \%$, ranging from $3.3 \%$ to $22.5 \%$. The average monthly value of nominal income per capita was $\mathrm{R} \$ 1069$ (approximately US $\$ 644$ in 2010).

The occurrence of multimorbidity was $22.2 \%$ (95\% CI 21.5 to 22.9 ) for $\geq 2$ morbidities and $10.2 \%$ (95\% CI 9.7 to 10.7 ) for $\geq 3$ morbidities. Irrespective of cut-off point, multimorbidity was higher in females, older people, individuals reporting white skin colour, who lived with a partner, had less schooling, had a private health plan and living in urban areas. At state level, multimorbidity was more frequent in states with higher education levels and wealthier states (table 1). States in the South of Brazil showed the highest occurrence of multimorbidity (see online Supplementary figure 1),

In the adjusted multilevel models, females had 1.86 (95\% CI 1.78 to 1.95 ) and 1.97 (CI $95 \% 1.85$ to 2.10 ) more odds of multimorbidity than males, for $\geq 2$ and $\geq 3$ morbidities, respectively. In all cases, every additional year of age increased by 1.06 times the odds of multiples diseases. Self-reported skin colour was not associated with multimorbidity in the adjusted models. On average, living with a partner increased by 1.15 times the odds of the outcome. Compared with individuals with $\geq 12$ years of schooling, adults with 1-8 years of schooling had more odds of multimorbidity (OR $1.4095 \%$ CI 1.32 to 1.49 , for $\geq 2$ diseases and OR $1.5895 \%$ CI 1.45 to 1.72 , for $\geq 3$ morbidities). In general, adults in the second and third wealthiest quintiles had greater odds of multimorbidity. Individuals with private health plans and who lived in urban areas had greater odds of multiple diseases. Individuals who lived in states with low-education and middle-education levels had less multimorbidity compared with states with high-education levels. With regard to income at state level, the higher multimorbidity difference was demonstrated simply by comparing low-income with high-income states (table 2). The associations stratified by region revealed a similar pattern to the whole Brazil, except to Central Western region in relation to lack of association of overall multimorbidity and private health plan, geographical area (observed to Southeastern region too) and schooling (no dose-response relationship) (table 3).

In the FA analysis, the KMO coefficient was 0.84 . Two patterns of morbidities explained $92 \%$ of total variance after rotation. The two components identified were: (1) cardiometabolic problems (HBP, heart attack, angina, heart failure, stroke, hypercholesterolaemia, diabetes and arthritis/rheumatism); (2) respiratory/mental/muscleskeletal disorders (arthritis/rheumatism, spinal column problem, asthma/wheezy bronchitis, COPD, work-related muscle-skeletal disorders, depression, bipolar disorder and kidney problem) (see online supplementary table 2).

The adjusted multilevel analyses of the two factors are presented in table 4. Overall, the results were similar to those observed in table 2. Females, older people, those with less schooling, those with intermediate asset ownership quintiles and who had private health plans showed more burden of factors. People who lived in rural geographical areas showed less burden of the cardiometabolic factor. Individuals with partners presented less burden of the respiratory/mental/muscle-skeletal factor compared with individuals who did not have a partner. Cardiometabolic and respiratory/mental/muscle-skeletal factors were greater when state-level education and income were lower. The cardiometabolic factor presented similar associations as overall multimorbidity to stratified analysis. As for the respiratory/mental/ muscle-skeletal factor did not show association with schooling in all regions (except to Northern) (table 5).

\section{DISCUSSION}

Multimorbidity frequency in Brazil is considerable; one in every five Brazilian adults had two or more morbidities and 1 in every 10 had 3or more morbidities. Individual and state-level inequalities suggest the complexity of factors and their relationship with multimorbidity occurrence. To our knowledge, this is the first representative Brazilian study to consider individual and contextual factors associated with multimorbidity and its clusters.

The study's national representativeness enables us to extrapolate frequencies for the whole Brazilian adult population. Considering 190755799 million adults in the most recent Brazilian population census (2010), we are able to infer that approximately 42.7 and 19.5 million Brazilian adults had two or more and three or more diseases, respectively. These results bring important challenges for the health system which will need to be more comprehensive to deal with the complexity of multimorbidity. Some of the issues are related to need to include multimorbidity in guidelines on reporting these problems 
Table 1 Description of the sample and multimorbidity frequency (Brazil 2013)

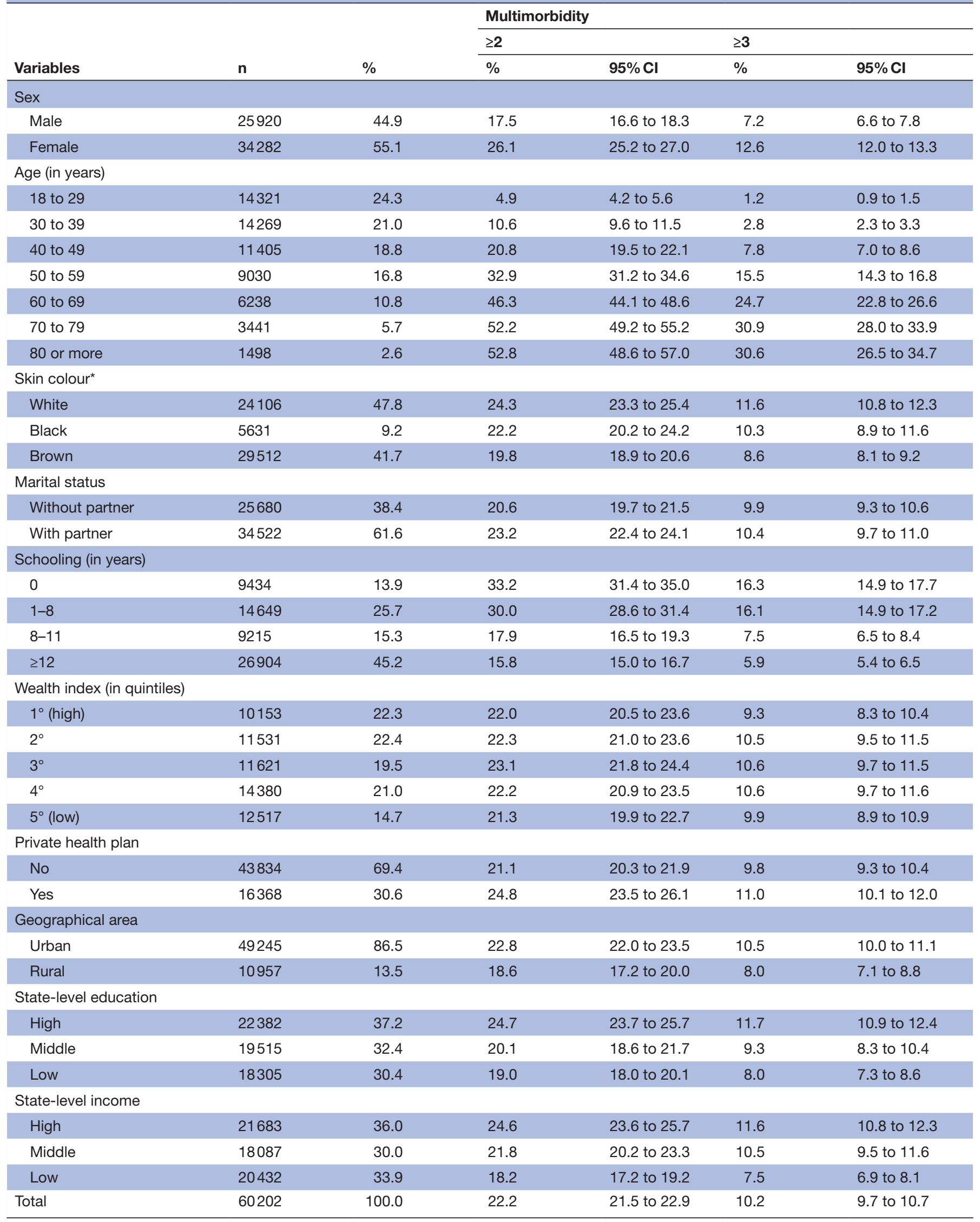




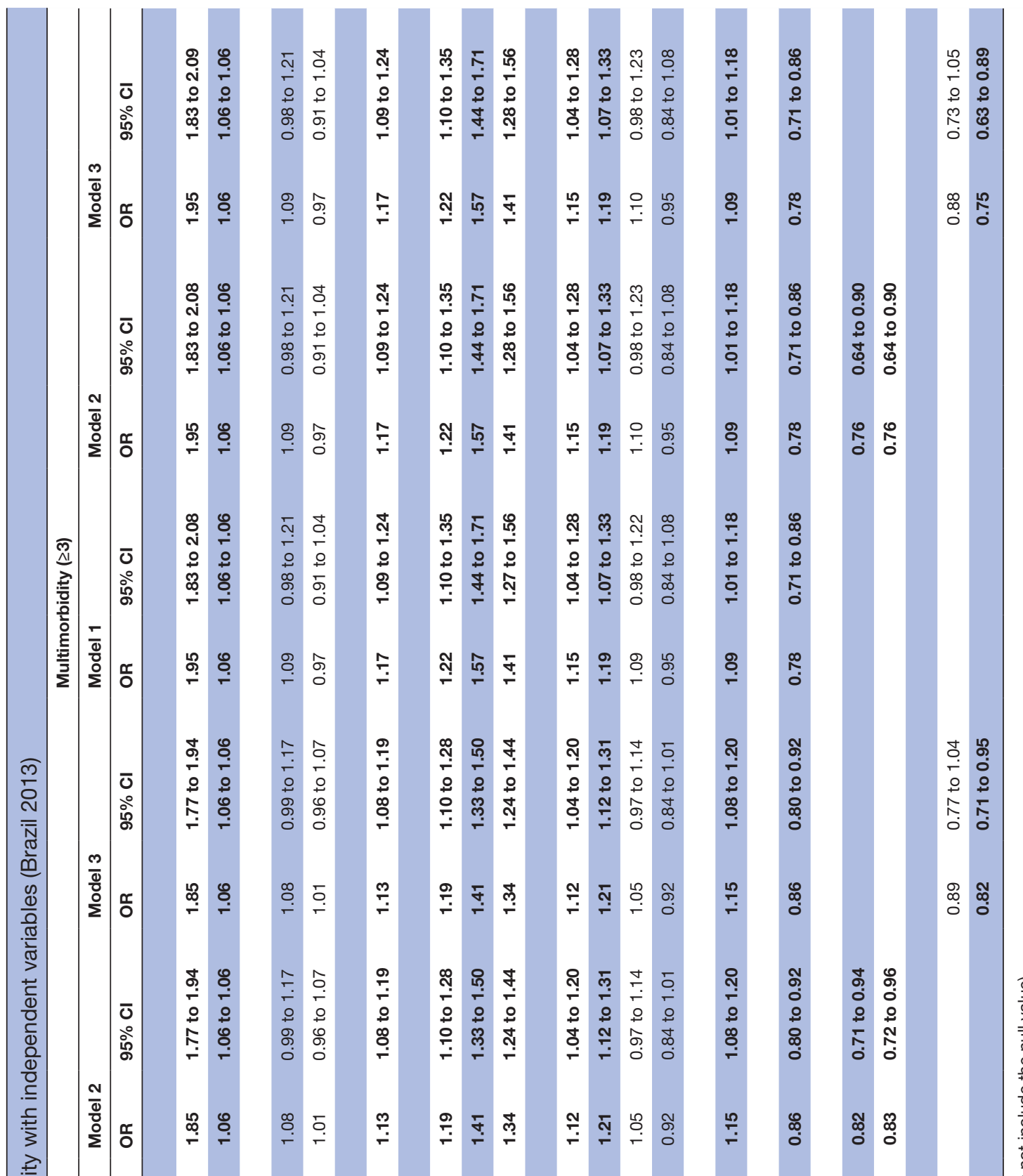




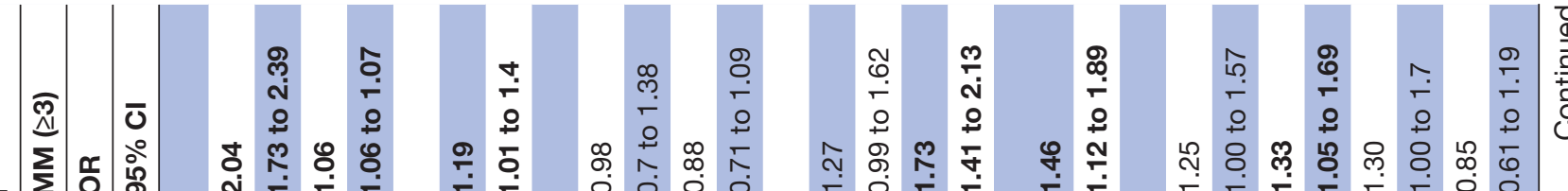

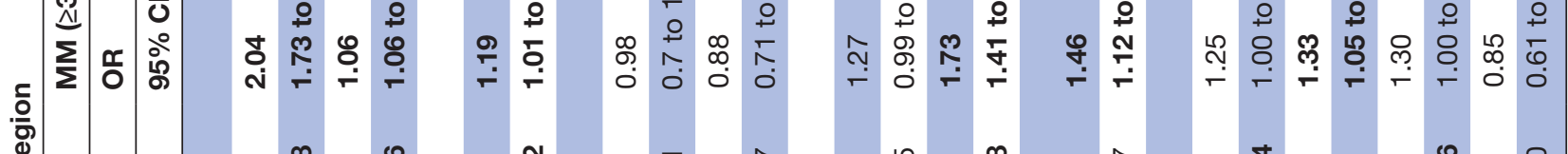

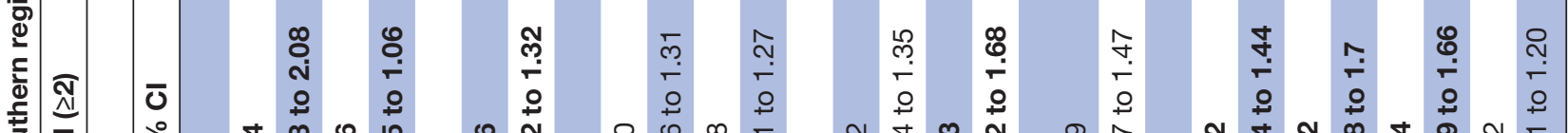

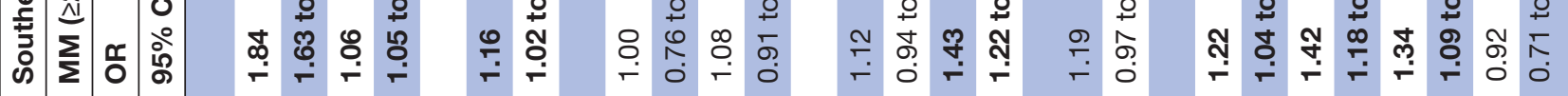

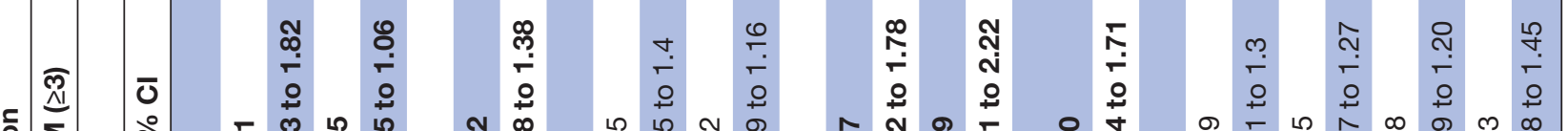

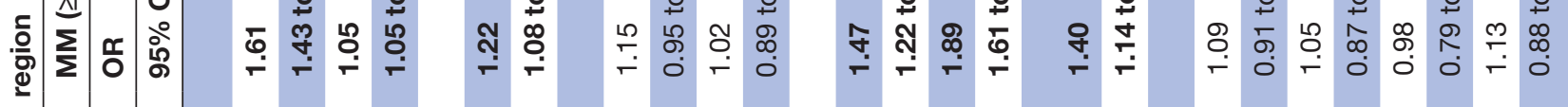
咅

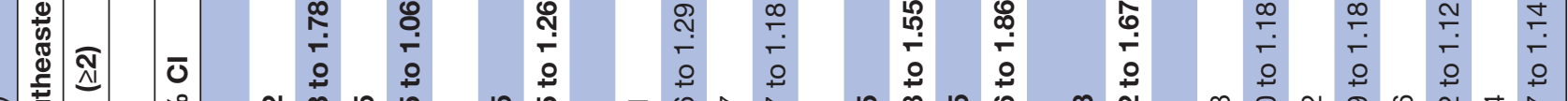

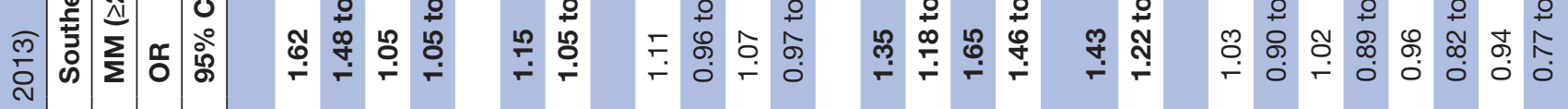
$\stackrel{\overline{\bar{N}}}{\underline{\frac{\pi}{n}}}$

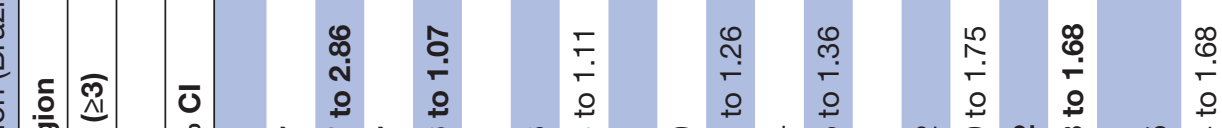

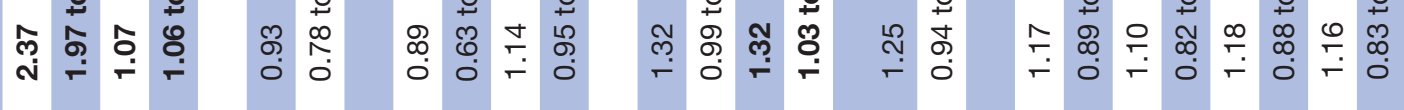

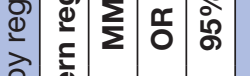

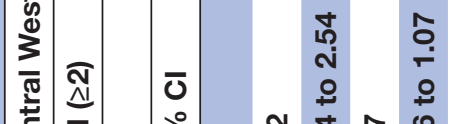

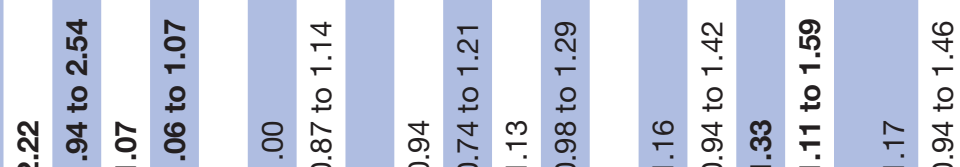

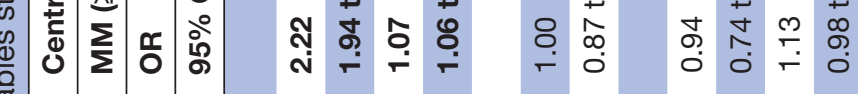
学

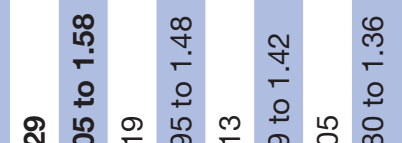
곤

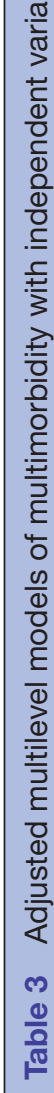

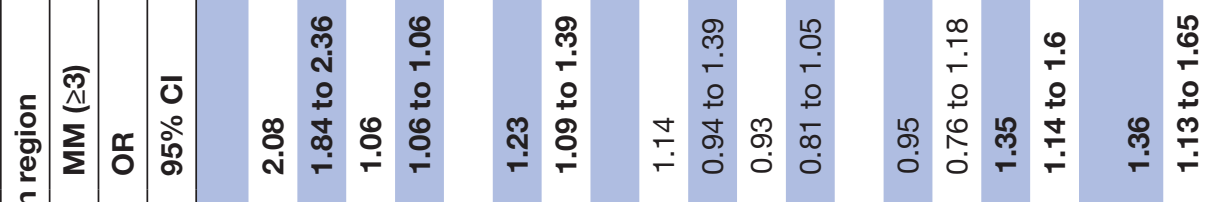

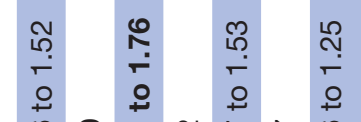
둥

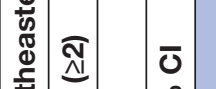

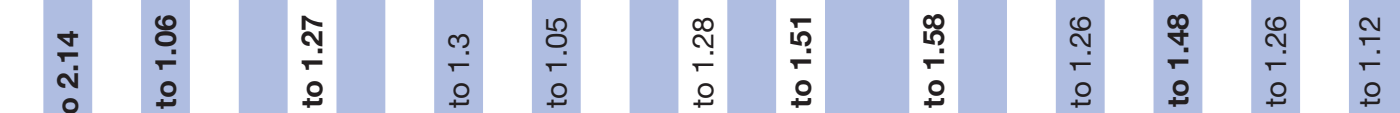

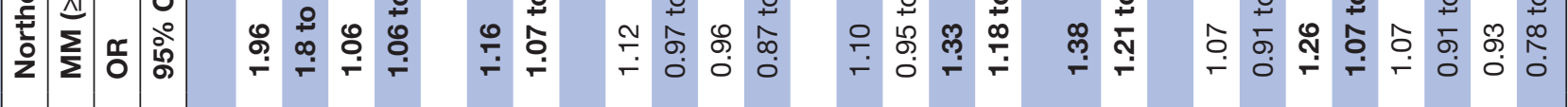

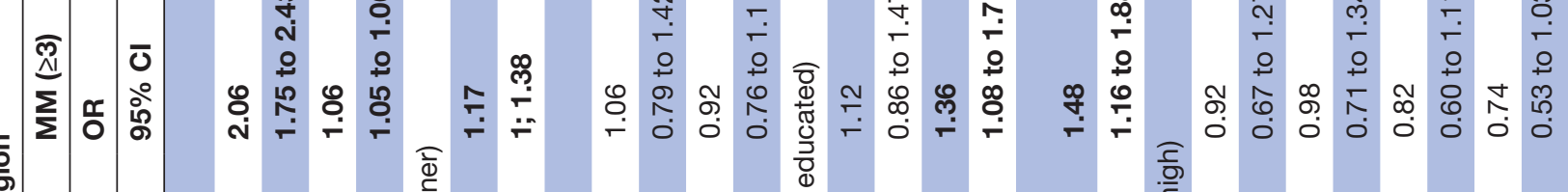

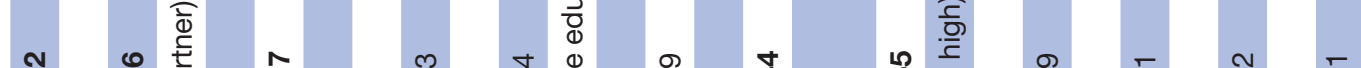

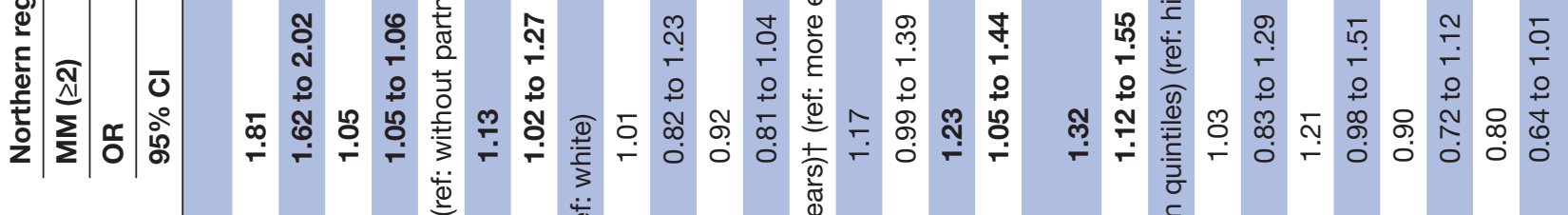

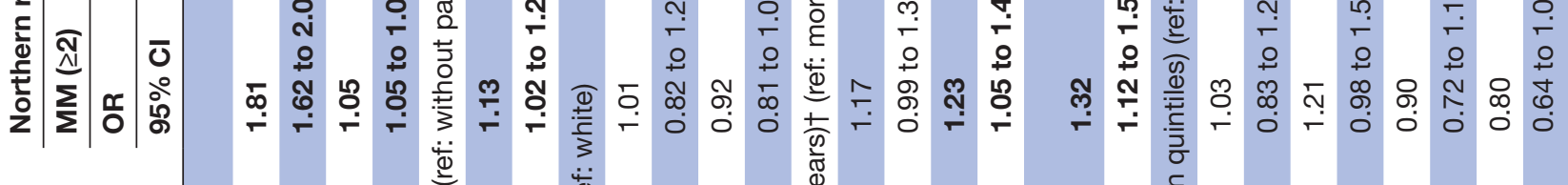

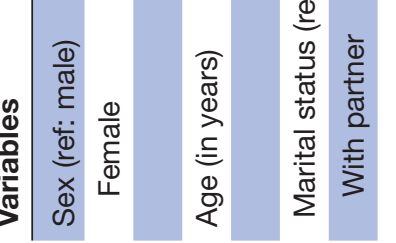

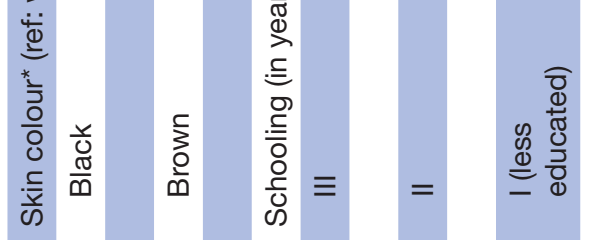

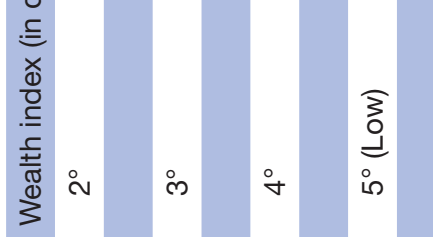




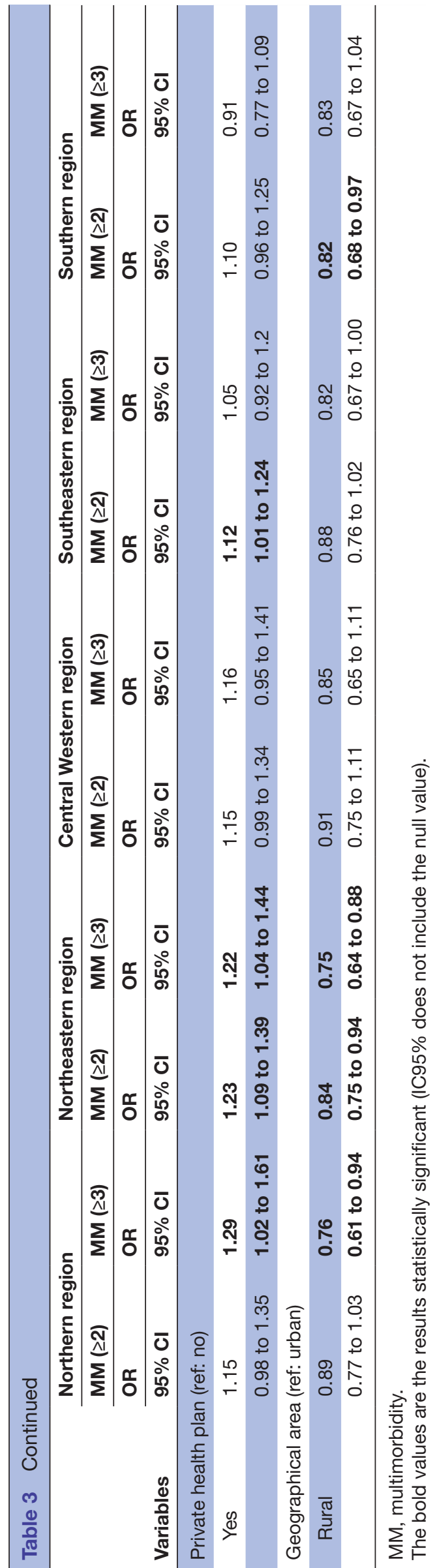

to health professionals, as well as giving more emphasis to multimorbidity on health-related university curricula.

Relative comparisons with Western countries reveal similar occurrence of two or more diseases in Spain ${ }^{23}$ (20.0\%; 95\% CI 18.8 to 21.2) and almost 10 percentage points less than in Scotland $^{24}$ (31.1\% 25 or more years) and Canada $^{25}$ (30.9\%; 95\% CI 29.5 to 32.4). In LMIC, estimates from countries (China, Ghana, India, Mexico, Russia and South Africa) included in the WHO Study on global AGEing and adult health (SAGE) Wave-1 (2007/10), found $21.9 \%$ (95\% CI 20.9 to 22.9 ) of multimorbidity occurrence ( $\geq 2$ diseases from a list from eight morbidities). ${ }^{5}$ This occurrence varied from $20.3 \%$ in China to $34.7 \%$ in Russia. In the present analysis, we used more diseases to construct multimorbidity (22 against eight in SAGE study). Even so, the prevalence found was, virtually, equal to these other LMIC countries, except for Russia.

In Brazil, our occurrence findings were slightly lower than the result found in a paper with same database (-2 pp). Furthermore, the authors found three clusters which differ of our results $(n=2)$ despite the resemblance of diseases grouping. ${ }^{12}$ These variations are explained by the differences among diseases selected to measure multimorbidity and analysis steps to obtain the clusters. The standardisation of multimorbidity operationalisation is an urgent call to avoid loss of consistency in the development of the area. ${ }^{4}$ Comparing with geographically located Brazilian results, our prevalence were lower than frequencies found in a Southern Brazilian city $(29.1 \%$; $95 \%$ CI 27.1 to 31.1 for $\geq 2$ morbidities and $14.3 \%$; $95 \%$ CI 12.8 to 15.8 for $\geq 3$ morbidities) despite the higher number of morbidities included in this study. ${ }^{10}$ The difference observed may be attributed to socioeconomic characteristics of Brazilian states. The states further South presented more development, wealth (both income and schooling) and higher life expectancy compared with other states ${ }^{13}$ which tend to increase the occurrence of multimorbidity at contextual level.

In terms of sociodemographic characteristics, females and older adults presented more multimorbidity in all Brazilian regions as found in previous Brazilian ${ }^{10} 11$ and international studies. ${ }^{26} 27$ Women tend to use health services more and to live longer than males, these being factors which explain part of the higher frequency in this group. Survivors older adults tend to be exposed to more physiological damages in lifetime that contribute to chronic disease incidence. ${ }^{28}$ In the same way, individuals who had partners had higher multimorbidity except to Central Western residents. The association between marital status should be more understanding through studies which include cultural assessment and its impact on chronic diseases development and diagnosis. One explanation is related to the fact that individuals with partner tend to use more health services increasing the probability of medical diagnosis. ${ }^{29}$

Regarding socioeconomic variables at individual level, our results follow the pattern found in overall analysis of a 


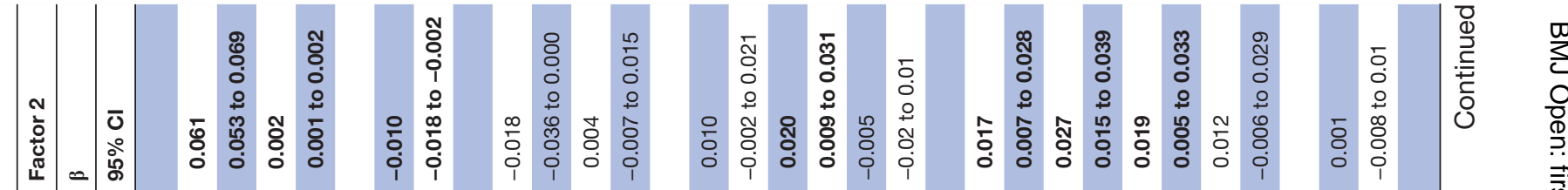

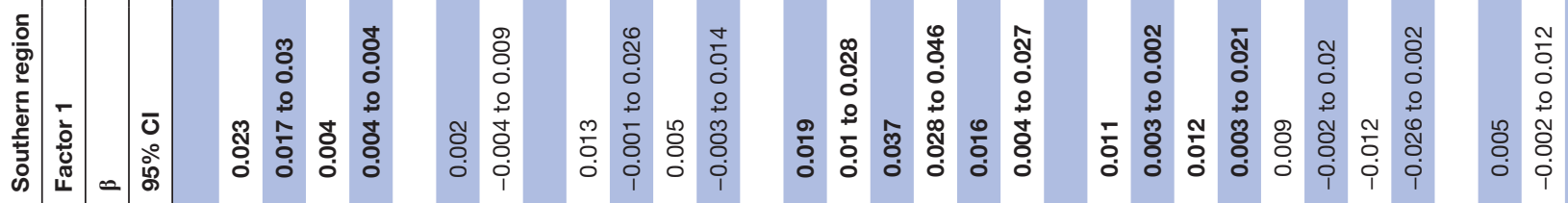

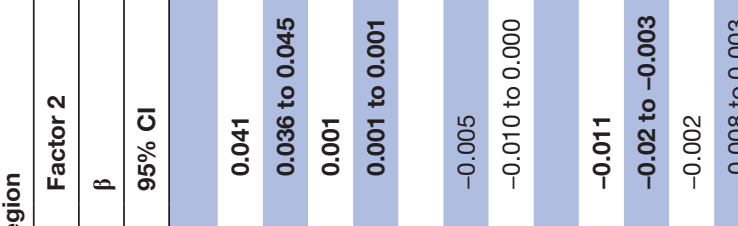

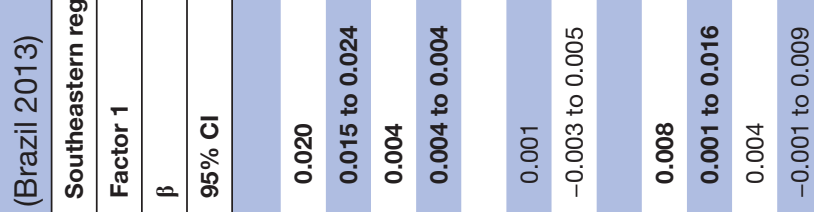

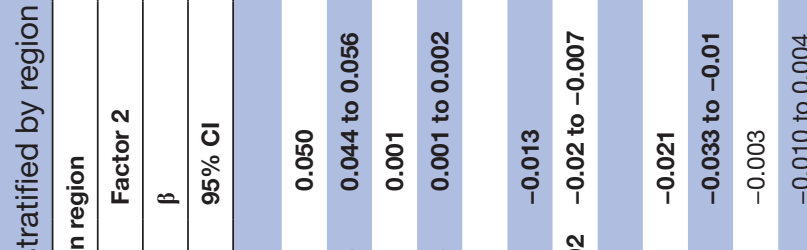

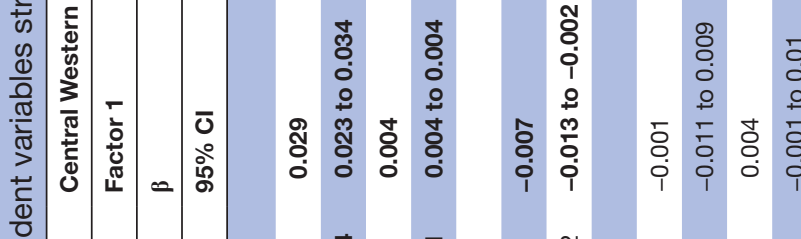

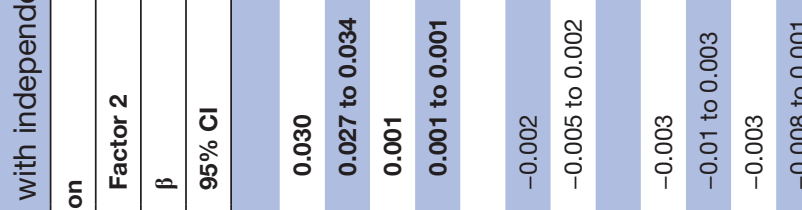

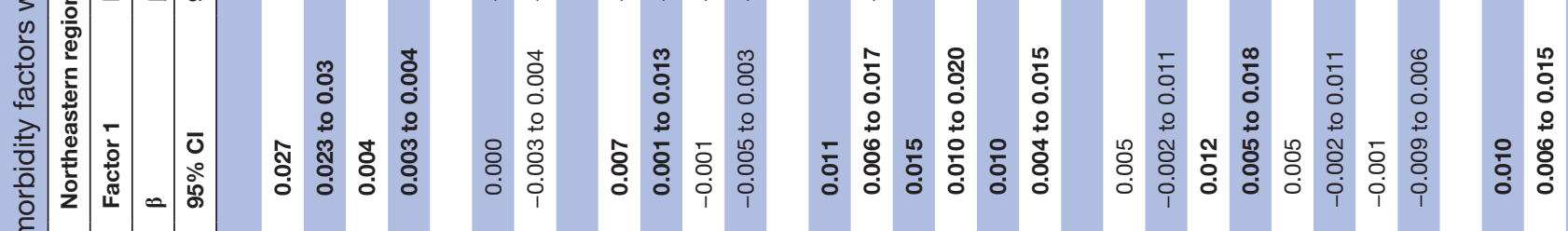

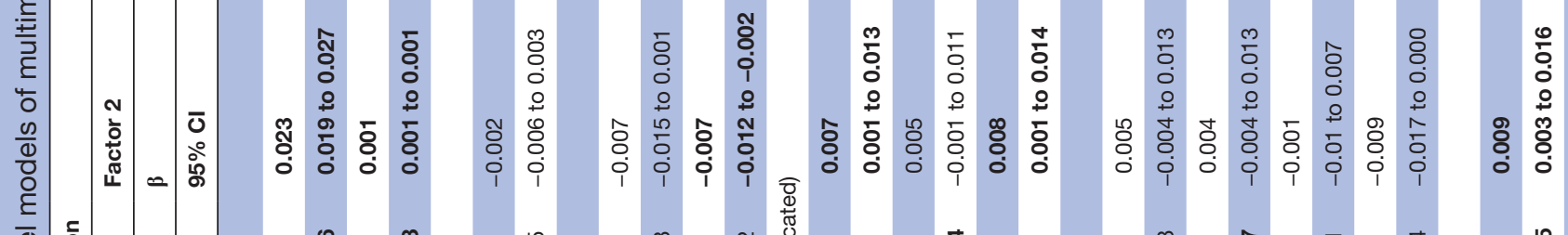

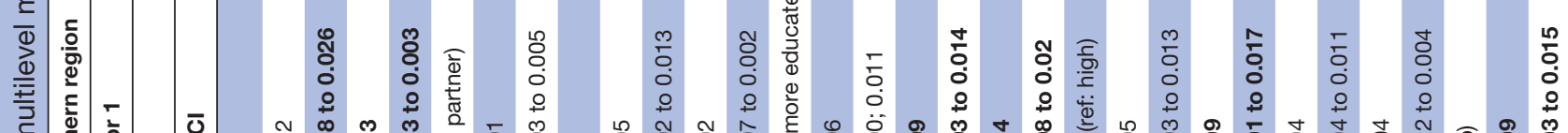

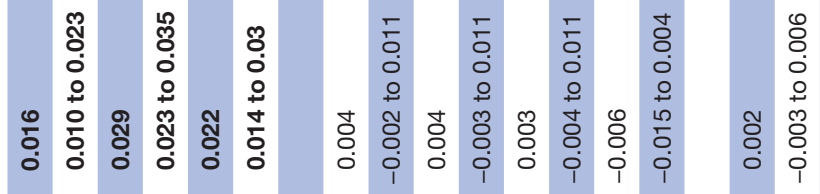

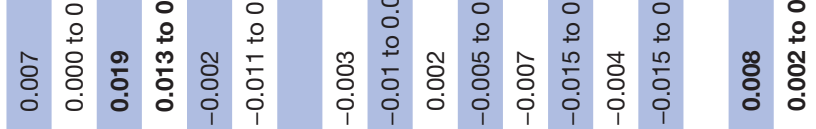

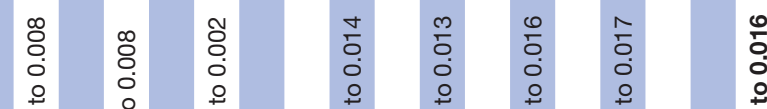

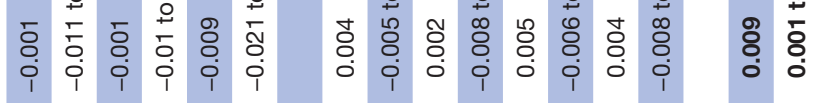

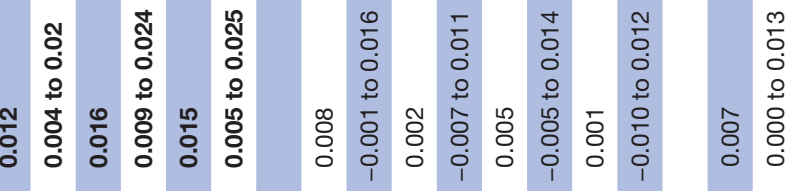

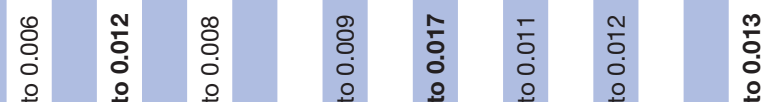

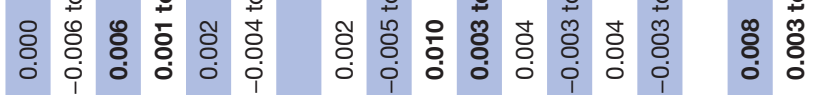

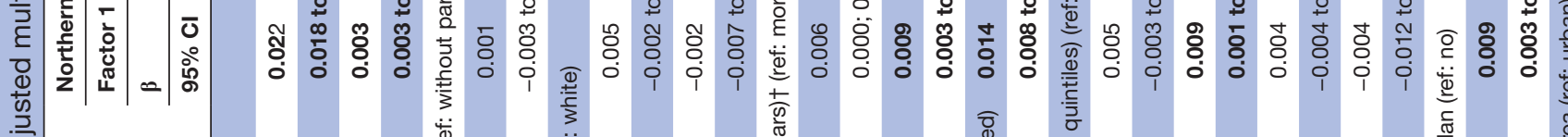

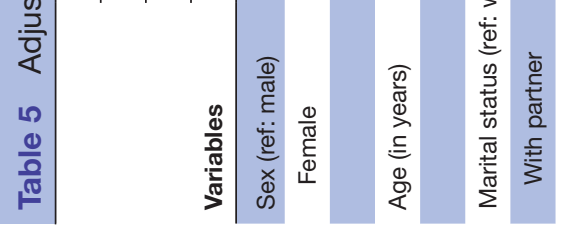

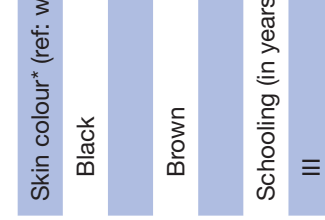

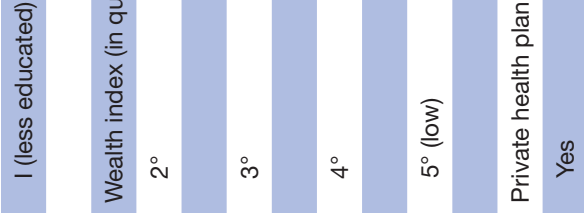


worldwide study ${ }^{27}$ and LMIC included in the SAGE study. Multimorbidity and its factors was not associated with wealth quintiles but presented association with education ${ }^{5}$ regardless Brazilian regions. In the present analysis, the middle wealth quintile strata and their clusters present more multimorbidity while showing a negative doseresponse relationship with education. These results may be explained by a strong relationship between educational attainment and all aspects of healthier life including those mainly related to better awareness of chronic disease risk factors. ${ }^{30}{ }^{31}$ Education level seems to be a more adequate socioeconomic indicator to evaluate multimorbidity inequalities due to its worldwide association with poor health outcomes and longevity and the persistent effect overtime. ${ }^{30}$ Except for the early effect of childhood health status on education, ${ }^{32}{ }^{33}$ chronic diseases in adult life tend to increase the risk of poverty (wealth index) ${ }^{34}$ but the effect on education tend to be less relevant since education is usually achieved is early life.

Having private health plans was associated with multimorbidity and its factors, except to Central Western and Southern. This may be explained, by the relationship with self-reported diagnosis (a fundamental characteristic of the outcome). Individuals with health plans tend to use health services more frequently regardless the presence of chronic conditions ${ }^{35} 36$ thus affording more diagnosis.

Individuals who lived in urban areas presented more multiple diseases. This was similar to results found in the adult population in South Africa ${ }^{37}$ and Catalonia (Spain). ${ }^{38}$ In spite of little Brazilian evidence on the topic, as well as the social, cultural and environment differences between rural-urban residents, people from rural areas had more difficulty in accessing health services in Brazil ${ }^{39}$ which may explain partially the differences between rural and urban residents in our results of the occurrence of self-reported medical diagnosis of multiple diseases.

The state-level differences observed reveal a paradoxical association. Instead of individual inequalities are pro-rich, state-level differences are pro-poor. These results might be explained by demographic differences between states in Brazil which may not be fully adjusted with individual demographic variables included in the analysis. Low income and low education in Brazilian states are concentrated in North and Northeast regions and show the poorest health-related indicators. ${ }^{13}$ The states further south (Rio Grande do Sul-27.2\% and Santa Catarina-27.1\%) present greater multimorbidity frequencies.

The two factors (cardiometabolic and respiratory/ mental/muscle-skeletal) found have some similarity to recent evidence ${ }^{4041}$ mainly related to cardiometabolic patterns. The respiratory/mental/muscle-skeletal data found was similar to results found in a worldwide study of people aged 50 or over. ${ }^{42}$ The majority of studies, especially with adult populations, found two or three patterns of diseases. These combinations of diseases suggest possible causal relationship between diseases or their risk factors. ${ }^{20}$ The cardiometabolic pattern showed a more 
well-known relationship between diseases. On the other hand, the relationship between respiratory, mental and muscle-skeletal disorders is less understood. The concomitant occurrence of these diseases is well described ${ }^{43}$ but understanding the biological plausibility of causal relationships will be a challenge for new studies. As a first step, more detailed and specific information about onset of diseases will be needed. At the same time, the use of approaches related to network analysis can be useful for a better understanding of causal relationships ${ }^{44}$ Even so, the results presented here may contribute to the inclusion of recommendations in Brazilian clinical guidelines about the relationship with chronic conditions, as well as to designing interventions/public policies considering the presence of multiple diseases in the same individual.

Some limitations of the study should be addressed. With the exception of depression, all the other morbidities were evaluated by self-reporting. This may provide a misclassification bias even though self-reported diagnosis is considered an adequate and common source of information used in population-based studies on multimorbidity. ${ }^{45}{ }^{46}$ Nevertheless, the lack of adequate information about diagnosis, including longitudinal information, limits the causal inference related to concomitant diseases expressed in factorial analysis. Furthermore, we are not able to evaluate the contextual determinants at neighbourhood level which may produce more complete associations with state-level differences.

The absolute and relative number of Brazilian individuals with multimorbidity was high. Addressing the complexity of multiple disease management for at least 19 million people will be a challenge for the health system. The clusters of diseases identified might contribute to strategies for the prevention and clinical care of these diseases. State and individual-level inequalities increase the problem reinforcing the need of a wide lens to organise health services and to decrease the inequities among the Brazilian population.

\author{
Author affiliations \\ ${ }^{1}$ Postgraduate Program in Nursing, Federal University of Pelotas, Pelotas, Rio \\ Grande do Sul, Brazil \\ ${ }^{2}$ Department of Epidemiology, School of Public Health, University of São Paulo, São \\ Paulo, Brazil \\ ${ }^{3}$ Indian Institute of Public Health, Public Health Foundation of India, Bhubaneswar, \\ India \\ ${ }^{4}$ Municipal Health Department of São Paulo, São Paulo, Brazil \\ ${ }^{5}$ Postgraduate Program in Epidemiology, Federal University of Pelotas, Pelotas, Rio \\ Grande do Sul, Brazil \\ ${ }^{6}$ School of Nursing, Universidad Industrial de Santander, Bucaramanga, Colombia \\ ${ }^{7}$ Department of Psychology, Federal University of Pelotas, Pelotas, Rio Grande do \\ Sul, Brazil \\ ${ }^{8}$ Faculty of Medicine, Federal University of Goiás, Goiânia, Goiás, Brazil
}

Contributors BPN designed the article, obtained and analysed the data, drafted the first version and revised the manuscript. ADPCF and FACF analysed the data and drafted and revised the manuscript. SP, DSCT, TRF, TNM, ET and LAF drafted and revised the manuscript. SRRB designed the article, drafted and revised the manuscript. All authors approved the final version of the manuscript.

Funding There are no funding related to the production of the paper. The Brazilian Ministry of Health financed the PNS survey. The funder of the survey played no role in the study design; collection, analysis and interpretation of data; writing of the report; or the decision to submit the article for publication.

Competing interests None declared.

Provenance and peer review Not commissioned; externally peer reviewed.

Data sharing statement All PNS data are available from the Brazilian Institute of Geography and Statistics website ().

Open Access This is an Open Access article distributed in accordance with the Creative Commons Attribution Non Commercial (CC BY-NC 4.0) license, which permits others to distribute, remix, adapt, build upon this work non-commercially, and license their derivative works on different terms, provided the original work is properly cited and the use is non-commercial. See: http://creativecommons.org/ licenses/by-nc/4.0/

(C) Article author(s) (or their employer(s) unless otherwise stated in the text of the article) 2017. All rights reserved. No commercial use is permitted unless otherwise expressly granted.

\section{REFERENCES}

1. Ryan A, Wallace E, O'Hara P, et al. Multimorbidity and functional decline in community-dwelling adults: a systematic review. Health Qual Life Outcomes 2015;13:1-13.

2. Fortin M, Lapointe L, Hudon C, et al. Multimorbidity and quality of life in primary care: a systematic review. Health Qual Life Outcomes 2004;2:51.

3. Nunes BP, Flores TR, Mielke Gl, et al. Multimorbidity and mortality in older adults: a systematic review and meta-analysis. Arch Gerontol Geriatr 2016;67:130-8.

4. Fortin M, Stewart M, Poitras ME, et al. A systematic review of prevalence studies on multimorbidity: toward a more uniform methodology. Ann Fam Med 2012;10:142-51.

5. Arokiasamy $\mathrm{P}$, Uttamacharya $\mathrm{U}$, Jain $\mathrm{K}$, et al. The impact of multimorbidity on adult physical and mental health in low- and middle-income countries: what does the study on global ageing and adult health (SAGE) reveal? BMC Med 2015;13:178.

6. Pati S, Agrawal S, Swain S, et al. Non communicable disease multimorbidity and associated health care utilization and expenditures in India: cross-sectional study. BMC Health Serv Res 2014;14:451.

7. Pati S, Swain S, Hussain MA, et al. Prevalence, correlates, and outcomes of multimorbidity among patients attending primary care in Odisha, India. Ann Fam Med 2015;13:446-50.

8. Pati S, Swain S, Hussain MA, et al. Prevalence and outcomes of multimorbidity in South Asia: a systematic review. BMJ Open 2015;5:e007235.

9. Andrade LH, Benseñor IM, Viana MC, et al. Clustering of psychiatric and somatic illnesses in the general population: multimorbidity and socioeconomic correlates. Braz J Med Biol Res 2010;43:483-91.

10. Nunes BP, Camargo-Figuera FA, Guttier M, et al. Multimorbidity in adults from a southern brazilian city: occurrence and patterns. Int $J$ Public Health 2016;61:1013-20.

11. Nunes BP, Thumé E, Facchini LA. Multimorbidity in older adults: magnitude and challenges for the brazilian health system. BMC Public Health 2015;15:1172.

12. Rzewuska M, de Azevedo-Marques JM, Coxon D, et al. Epidemiology of multimorbidity within the brazilian adult general population: evidence from the 2013 National Health survey (PNS 2013). PLoS One 2017;12:e0171813.

13. Paim J, Travassos C, Almeida C, et al. The brazilian health system: history, advances, and challenges. The Lancet 2011;377:1778-97.

14. Schmidt MI, Duncan BB, Azevedo e Silva G, et al. Chronic noncommunicable diseases in Brazil: burden and current challenges. Lancet 2011;377:1949-61.

15. Andrade LH, Wang YP, Andreoni S, et al. Mental disorders in megacities: findings from the São Paulo megacity mental health survey, Brazil. PLoS One 2012;7:e31879.

16. Damacena GN, Szwarcwald CL, Malta DC, et al. The development of the National Health survey in Brazil, 2013. Epidemiologia e Serviços de Saúde 2015;24:197-206.

17. PRBd S-J, MPSd F, GdA A, et al. Sampling design for the National Health Survey, 2013. Epidemiologia e Serviços de Saúde 2015;24:207-16.

18. Santos IS, Tavares BF, Munhoz TN, et al. Sensibilidade e especificidade do Patient Health Questionnaire-9 (PHQ-9) entre adultos da população geral. Cad Saude Publica 2013;29:1533-43. 
19. Harrison C, Britt H, Miller G, et al. Examining different measures of multimorbidity, using a large prospective cross-sectional study in australian general practice. BMJ Open 2014;4:e004694.

20. Schäfer I, von Leitner EC, Schön G, et al. Multimorbidity patterns in the elderly: a new approach of disease clustering identifies complex interrelations between chronic conditions. PLOS One 2010;5:e15941.

21. Kubinger K. On artificial results due to using factor analysis for dichotomous variables. Psycology Science 2003;45

22. Norman G, Streiner D. Principal Components and factor analysis. fooling around with factors. biostatistics: the bare essentials. 3 ed. Hamilton: Bc Decker, 2008.

23. Garin N, Olaya B, Perales $\mathrm{J}$, et al. Multimorbidity patterns in a national representative sample of the spanish adult population. PLOS One 2014:9:e84794.

24. Barnett K, Mercer SW, Norbury M, et al. Epidemiology of multimorbidity and implications for health care, research, and medical education: a cross-sectional study. Lancet 2012;380:37-43.

25. Agborsangaya CB, Ngwakongnwi E, Lahtinen M, et al. Multimorbidity prevalence in the general population: the role of obesity in chronic disease clustering. BMC Public Health 2013;13:1161.

26. Violan C, Foguet-Boreu Q, Flores-Mateo G, et al. Prevalence, determinants and patterns of multimorbidity in primary care: a systematic review of Observational Studies. PLoS One 2014;9:e102149.

27. Afshar S, Roderick PJ, Kowal P, et al. Multimorbidity and the inequalities of global ageing: a cross-sectional study of 28 countries using the World Health surveys. BMC Public Health 2015;15:1-10.

28. Salive ME. Multimorbidity in older adults. Epidemiol Rev 2013;35:75-83

29. Mendoza-Sassi R, Béria JU. Health services utilization: a systematic review of related factors. Cad Saude Publica 2001;17:819-32.

30. Montez JK, Friedman EM. Educational attainment and adult health: under what conditions is the association causal? Soc Sci Med 2015;127:1-7.

31. CSDH. Closing the gap in a generation: health equity through action on the social determinants of health. final Report of the Commission on Social Determinants of Health. Geneva: World Health Organization, 2008.

32. Haas SA, Glymour MM, Berkman LF. Childhood health and labor market inequality over the life course. J Health Soc Behav 2011;52:298-313.
33. Case A, Fertig A, Paxson C. The lasting impact of childhood health and circumstance. J Health Econ 2005;24:365-89.

34. Callander EJ, Schofield DJ. The risk of falling into poverty after developing heart disease: a survival analysis. BMC Public Health 2016;16:570.

35. Skinner EH, Foster M, Mitchell G, et al. Effect of health insurance on the utilisation of allied health services by people with chronic disease: a systematic review and meta-analysis. Aust $J$ Prim Health 2014;20:9-19.

36. Chung RY, Mercer SW, Yip BH, et al. The association between types of regular primary care and hospitalization among people with and without multimorbidity: a household survey on 25,780 chinese. Sci Rep 2016;6:29758.

37. Alaba O, Chola L. The social determinants of multimorbidity in South Africa. Int J Equity Health 2013;12:63-10.

38. Foguet-Boreu Q, Violan C, Roso-Llorach A, et al. Impact of multimorbidity: acute morbidity, area of residency and use of health services across the life span in a region of south Europe. BMC Fam Pract 2014;15:1-11.

39. Macinko J, Lima Costa MF. Access to, use of and satisfaction with health services among adults enrolled in Brazil's Family Health Strategy: evidence from the 2008 National Household Survey. Trop Med Int Health 2012;17:36-42.

40. Prados-Torres A, Calderón-Larrañaga A, Hancco-Saavedra J, et al. Multimorbidity patterns: a systematic review. J Clin Epidemiol 2014:67:254-66.

41. Prados-Torres A, Poblador-Plou B, Calderón-Larrañaga A, et al. Multimorbidity patterns in primary care: interactions among chronic diseases using factor analysis. PLoS One 2012;7:e32190.

42. Garin N, Koyanagi A, Chatterii S, et al. Global multimorbidity patterns: a Cross-Sectional, Population-Based, Multi-Country study. J Gerontol A Biol Sci Med Sci 2016;71:205-14.

43. Barnes PJ, Celli BR. Systemic manifestations and comorbidities of COPD. Eur Respir J 2009;33:1165-85.

44. Faner R, Cruz T, López-Giraldo A, et al. Network medicine, multimorbidity and the lung in the Elderly. Eur Respir $J$ 2014:44:775-88.

45. Huntley AL, Johnson R, Purdy S, et al. Measures of multimorbidity and morbidity burden for use in primary care and community settings: a systematic review and guide. Ann Fam Med 2012;10:134-41.

46. Violán C, Foguet-Boreu Q, Hermosilla-Pérez E, et al. Comparison of the information provided by electronic health records data and a population health survey to estimate prevalence of selected health conditions and multimorbidity. BMC Public Health 2013;13:251. 
Correction: Contextual and individual inequalities of multimorbidity in Brazilian adults: a cross-sectional national-based study

Nunes BP, Chiavegatto Filho ADP, Pati S, et al. Contextual and individual inequalities of multimorbidity in Brazilian adults: a cross-sectional national-based study. BMJ Open 2017;7:e015885. doi: 10.1136/bmjopen-2017-015885.

This article was previously published with some errors.

In table 1 and supplementary table 1 , the percentages of the descriptive analyses, no full postestimation of complex sampling are performed resulting in minor discrepancies on decimal places. Absolute numbers are not affected. The issue didn't affect the main results or the conclusions of the paper. The corrected numbers are displayed below.

Table 1 Description of the sample and multimorbidity frequency. Brazil, 2013

\begin{tabular}{|ccc}
\hline Variables & \% originally published & \% corrected \\
\hline Sex & & \\
\hline Male & 44.9 & 47.1 \\
\hline Female & 55.1 & 52.9 \\
\hline Age (in years) & & \\
\hline 18 to 29 & 24.3 & 26.1 \\
\hline 30 to 39 & 21.0 & 21.6 \\
\hline 40 to 49 & 18.8 & 18.1 \\
\hline 50 to 59 & 16.8 & 16.2 \\
\hline 60 to 69 & 10.8 & 10.2 \\
\hline 70 to 79 & 5.7 & 5.4 \\
\hline 80 or more & 2.6 & 2.5 \\
\hline Skin color & & \\
\hline White & 47.8 & 47.5 \\
\hline Black & 9.2 & 9.2 \\
\hline Brown & 41.7 & 42.0 \\
\hline Marital status & & \\
\hline Without partner & 38.4 & 38.8 \\
\hline With partner & 61.6 & 61.2 \\
\hline Schooling (in years) & & \\
\hline 0 & 13.9 & 13.7 \\
\hline $1-8$ & 25.7 & 25.3 \\
\hline $8-11$ & 15.3 & 15.5 \\
\hline Wealth index (in quintiles) $^{\circ}$ & 45.2 & 45.5 \\
\hline $2^{\circ}$ (High) & & 22.2 \\
\hline $3^{\circ}$ & 22.3 & 14.9 \\
\hline $5^{\circ}$ (Low) & 19.5 & 69.7 \\
\hline No & 21.0 & \\
\hline
\end{tabular}




\begin{tabular}{lcc}
\hline Variables & \% originally published & \% corrected \\
\hline Yes & 30.6 & 30.3 \\
Geographical area & & \\
Urban & 86.5 & 86.2 \\
\hline Rural & 13.5 & 13.8 \\
\hline State-level education & & \\
High & 37.2 & 37.2 \\
Middle & 32.4 & 32.4 \\
\hline Low & 30.4 & 30.4 \\
\hline State-level income & & \\
High & 36.0 & 36.0 \\
Middle & 30.0 & 30.1 \\
Low & 33.9 & 33.9 \\
\hline Total & 100.0 & 100.0 \\
\hline
\end{tabular}

Supplementary table 1 Individual prevalence, duration and number of comorbidities for each morbidity evaluated. Brazil, 2013

\begin{tabular}{lllll}
\hline & \multicolumn{2}{l}{$\begin{array}{l}\text { Individual prevalence } \\
\text { originally published }\end{array}$} & \multicolumn{2}{l}{$\begin{array}{l}\text { Individual prevalence } \\
\text { corrected }\end{array}$} \\
\cline { 2 - 5 } Morbidities & \% & $\mathbf{( 9 5 \%} \mathbf{C l})$ & \% & (95\% Cl) \\
\hline High Blood Pressure & 22.3 & 21.7 to 23.0 & 21.4 & 20.9 to 22.0 \\
\hline Spinal column problem & 19.0 & 18.3 to 19.7 & 18.4 & 17.7 to 19.1 \\
\hline Hypercholesterolemia & 8.4 & 8.0 to 8.8 & 8.1 & 7.7 to 8.4 \\
\hline Arthritis/rheumatism & 6.7 & 6.4 to 7.1 & 6.4 & 6.1 to 6.8 \\
\hline Diabetes & 6.5 & 6.2 to 6.9 & 6.2 & 5.9 to 6.6 \\
\hline Asthma/wheezy bronchitis & 4.4 & 4.1 to 4.8 & 4.4 & 4.1 to 4.7 \\
\hline Depression & 4.2 & 3.9 to 4.5 & 4.1 & 3.9 to 4.4 \\
\hline Worktorelated muscle-skeletal disorders & 2.5 & 2.2 to 2.8 & 2.4 & 2.2 to 2.7 \\
\hline Cancer & 1.9 & 1.7 to 2.2 & 1.8 & 1.7 to 2.0 \\
\hline Another heart disease & 1.9 & 1.6 to 2.1 & 1.8 & 1.6 to 2.1 \\
\hline Stroke & 1.6 & 1.4 to 1.8 & 1.5 & 1.4 to 1.7 \\
\hline Kidney problem & 1.5 & 1.3 to 1.7 & 1.4 & 1.3 to 1.6 \\
\hline Heart attack & 1.3 & 1.2 to 1.5 & 1.2 & 1.1 to 1.4 \\
\hline Heart failure & 1.2 & 1.1 to 1.4 & 1.2 & 1.0 to 1.3 \\
\hline Bronchitis & 1.0 & 0.8 to 1.1 & 1.0 & 0.8 to 1.1 \\
\hline Angina & 0.8 & 0.7 to 0.9 & 0.8 & 0.7 to 0.9 \\
\hline Emphysema & 0.5 & 0.4 to 0.6 & 0.4 & 0.3 to 0.5 \\
\hline Another lung disease & 0.5 & 0.4 to 0.6 & 0.5 & 0.4 to 0.6 \\
\hline Bipolar disorder & 0.4 & 0.3 to 0.5 & 0.4 & 0.3 to 0.5 \\
\hline Another mental disease & 0.3 & 0.2 to 0.4 & 0.3 & 0.2 to 0.4 \\
\hline Schizophrenia & 0.2 & 0.2 to 0.3 & 0.2 & 0.2 to 0.3 \\
\hline Obsessive Compulsive Disorder (OCD) & 0.2 & 0.1 to 0.2 & 0.2 & 0.1 to 0.2 \\
\hline & & & &
\end{tabular}

In reference 17, the last names of the authors were abbreviated. They should read as follows:

Souza-Junior PRB, Freitas MPS, Antonaci GA, et al. Sampling design for the National Health Survey, 2013. Epidemiologia e Serviços de Saúde 2015;24:207-16. 
Open access This is an open access article distributed in accordance with the Creative Commons Attribution Non Commercial (CC BY-NC 4.0) license, which permits others to distribute, remix, adapt, build upon this work non-commercially, and license their derivative works on different terms, provided the original work is properly cited, appropriate credit is given, any changes made indicated, and the use is non-commercial. See: http://creativecommons.org/licenses/by-nc/4.0/.

C Author(s) (or their employer(s)) 2018. Re-use permitted under CC BY-NC. No commercial re-use. See rights and permissions. Published by BMJ.

BMJ Open 2018;8:e015885corr1. doi:10.1136/bmjopen-2017-015885corr1

(A) Check for updates 
Correction: Contextual and individual inequalities of multimorbidity in Brazilian adults: a cross-sectional national-based study

Nunes BP, Chiavegatto Filho ADP, Pati S, et al. Contextual and individual inequalities of multimorbidity in Brazilian adults: a cross-sectional national-based study BMJ Open 2017;7:e015885. doi: 10.1136/bmjopen-2017-015885.

This article was previously published with an error.

Two conditions used to create multimorbidity were incorrectly explained in the methods section:

1. Hypercholesterolaemia has included individuals presenting the condition for more than 1 year. The information about the time was not described in the original version.

2. Spinal column problem was based on self-reported information from the interviewee. In the original text, the condition was described as a self-reported medical diagnosis.

Open access This is an open access article distributed in accordance with the Creative Commons Attribution Non Commercial (CC BY-NC 4.0) license, which permits others to distribute, remix, adapt, build upon this work non-commercially, and license their derivative works on different terms, provided the original work is properly cited, appropriate credit is given, any changes made indicated, and the use is non-commercial. See: http://creativecommons.org/licenses/by-nc/4.0/.

(C) Author(s) (or their employer(s)) 2019. Re-use permitted under CC BY-NC. No commercial re-use. See rights and permissions. Published by BMJ.

BMJ Open 2019;9:e015885corr2. doi:10.1136/bmjopen-2017-015885corr2

D) Check for updates 